\section{Developmental \\ Neuroscience}

Antonarakis, S.E. 404

Baamonde, C. 442

Baldini, A. 404

Belichenko, P.V. 404

Bhattacharyya, S. 451

Biswas, R. 451

Budimirovic, D.B. 379

Burns, M.P. 395

Chakrabarti, L. 428

Corbin, J.G. 365, 395

Costa, A.C.S. 414

Dierssen, M. 442
Flórez, J. 442

Fu, D. 404

Galdzicki, Z. 451

Gallo, V. 428

Grover, D. 451

Haydar, T.F. 428

Holman, D. 451

Huntsman, M.M. 349

Kaufmann, W.E. 379

Keck-Wherley, J. 451

Kleschevnikov, A.M. 404

Liu, C. 404
Lombardini, E.D. 451

Martin, B.S. 349

Martínez-Cué, C. 442

Mobley, W.C. 404

Olmos-Serrano, J.L. 365, 395

Paluszkiewicz, S.M. 349

Scafidi, J. 428

Tranfaglia, M.R. 337

Verma, R. 451

$\mathrm{Xu}, \mathrm{X} .451$

Yu, Y.E. 404

Zhang, L. 404

\title{
Subject Index Vol. 33, No. 5, 2011
}

Adenylyl cyclase 442

Alzheimer's disease 414

Amygdala 349, 365

Animal model 365

Autism spectrum disorder(s) 337, 349, 379

Autistic features 379

Behavior 337, 365, 395

Blood 451

Cell proliferation 428

Cerebral cortex 349

Creb1 451

Cyclic adenosine monophosphate 442

Developmental cognitive disabilities 404

- disability/-ies 395, 414

- disorder 349

Disease mechanisms 337

Down syndrome 404, 428, 442

Drug therapy 414

Emotions 365

Environmental enrichment 428, 442
Ezh2 451

Fear 365

- conditioning 365

Fragile X mental retardation protein 349

- - syndrome 365, 379, 395

G protein transduction 442

GABA 365

$\mathrm{GABA}_{\mathrm{A}}$ receptor agonist 395

Gliogenesis 428

Hippocampus 428

Human trisomy 21404

Inhibition 349

Inhibitory circuits 365

Intellectual disability 379, 414

Lung 451

Mecp2 451

Memantine 414

Mental illness 365

miR-155 451

miR-214 451

miR-223 451
miR-802 451

Mouse model(s) 395, 404

Neurogenesis 428

N-methyl-D-aspartate receptors 414

Pathophysiology 337

Phenotype 337

Phosphatidylinositol 4,5-bisphosphate 442

Phospholipase C 442

Postnatal development 442

Psychopharmacology 337

Ship1 451

Social anxiety 379

- withdrawal 379

Subventricular zone 428

Synapse 349

Targeted chromosome manipulation 404

Trisomic mouse model 442

Trisomy 21414

Ts65Dn 442

- mice 414 